\title{
Soft disc herniation in patients with lumbar stenosis
}

\section{Martin H. Savitz, M.D.}

Divisions of Neurosurgery, Departments of Surgery, Nyack and Good Samaritan Hospitals, Rockland County, New York

Over a period of 25 years, a surgical technique has evolved for removal of a soft disc herniation in patients with sciatica and lumbar stenosis demonstrated on neuroradiological studies. Initially emphasis was placed on decompression of the entire narrow spinal canal when there was evidence of single nerve root involvement and no history of neurogenic claudication. The author has performed 12 microsurgical discectomies since 1984 and eight percutaneous endoscopic discectomies over the past 6 years that have been successful in relieving radiculitis and radiculopathy in cases of a single herniated nucleus pulposus, even in the presence of a stenotic canal. No patient complained of generalized numbness, weakness, or pain in the lower extremities while walking. After at least 1 year of follow up, the 20 patients who underwent microsurgical or arthroscopic procedures limited to removing the ruptured disc have not required more extensive decompression.

\section{Key Words * lumbar stenosis * herniated disc * microsurgical discectomy * arthroscopic discectomy}

Laminectomy has been recommended to avoid failed-back surgery syndrome when there is frank herniation of a lumbar disc at the level of a hypertrophic zygapophyseal joint.[1] Prior to 1984, 18 patients with lumbar stenosis over several segments and a single herniated disc underwent extensive midline laminectomies prior to multiple facetectomies and foraminotomies to avoid excessive manipulation of the nerve root during exploration of the disc space. Malis[6] pointed out that identification of a narrow lumbar canal does not automatically dictate extensive surgical decompression. He maintained that microsurgical discectomy could provide permanent relief of radiculitis and radiculopathy in the patient with congenital or acquired stenosis who had a clear history of acute rupture of a nucleus pulposus.

\section{CLINICAL MATERIAL AND METHODS}

The patient population was composed of 14 men and six women ranging in age from 60 to 82 years. The L5-S1 disc was herniated in six patients, the L4-5 disc in 12 patients, and the L3-4 disc in two patients. The diagnosis was made by computerized tomography (CT) (Fig. 1) or magnetic resonance (MR) imaging (Fig. 2). Preoperatively, all of the patients were confined to extensive periods of bed rest due to sciatica and muscle spasm. No patient complained of generalized numbness, weakness, or pain in the 
lower extremities while walking.

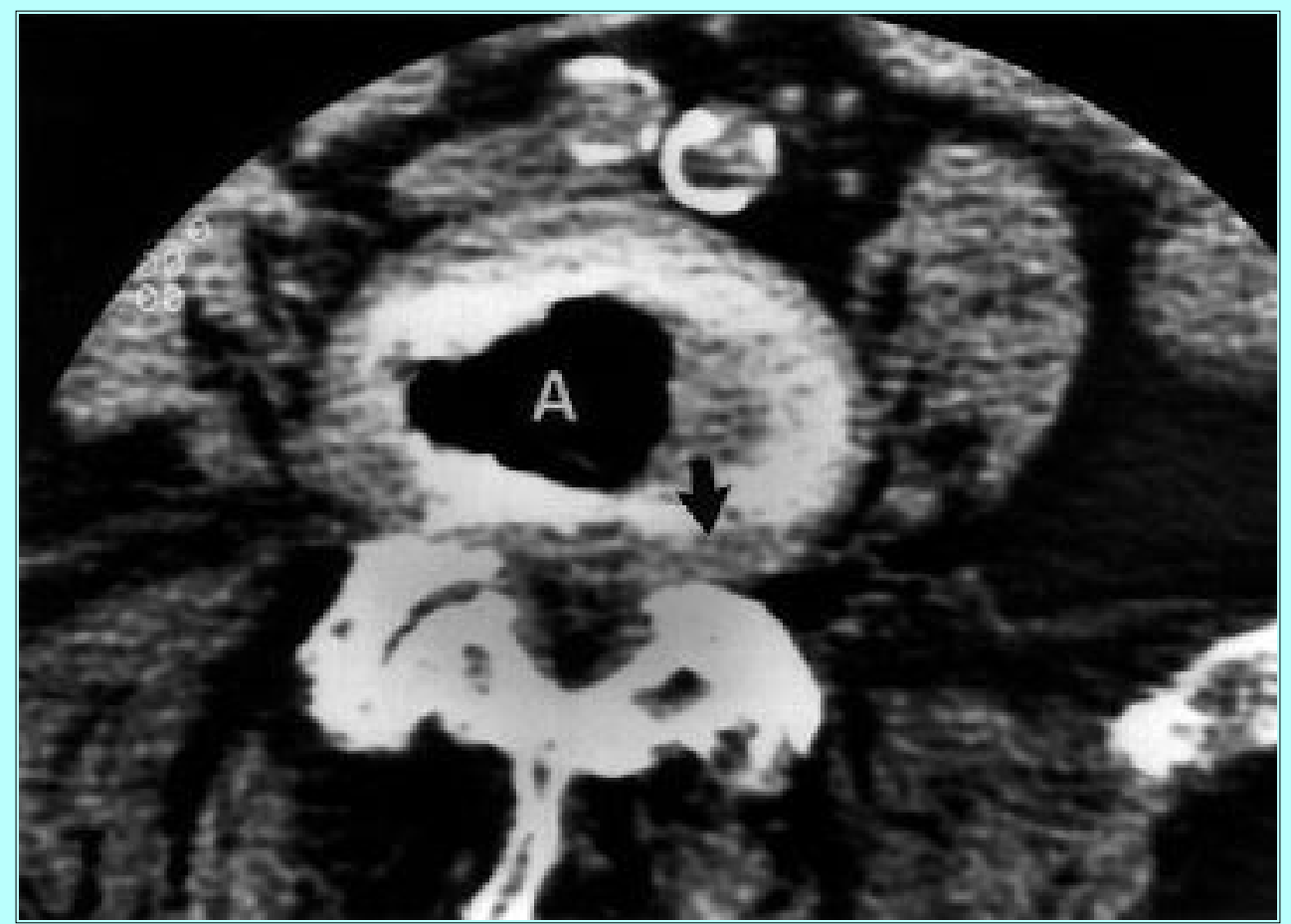

Fig. 1. Computerized tomography scan showing air (A) consistent with degenerative disc disease as well as soft disc herniation (arrow). Note superimposed overgrowth of the facets.

The term "minilaminotomy"[12] was coined to describe microsurgical techniques that not only relieved segmental spondylosis and lateral recess syndrome but also provided adequate access to the prolapsed disc. The operative procedure involved the use of simple prone positioning, a 4-cm incision, standard instruments, $\mathrm{X}$-ray guidance, a fiberoptic head light, X 4.5 binocular loupes, and bipolar coagulation. Laminotomy was necessary in most cases to visualize the superiorly positioned intervertebral space. Medial facetectomy and foraminotomy avoided nerve root retraction. Whereas curettage of the cartilaginous plates was specifically avoided, removal of 6 to $10 \mathrm{~g}$ of disc material was possible with pituitary rongeurs and by direct excision of scarred-in fragments with a No. 11 scalpel. 


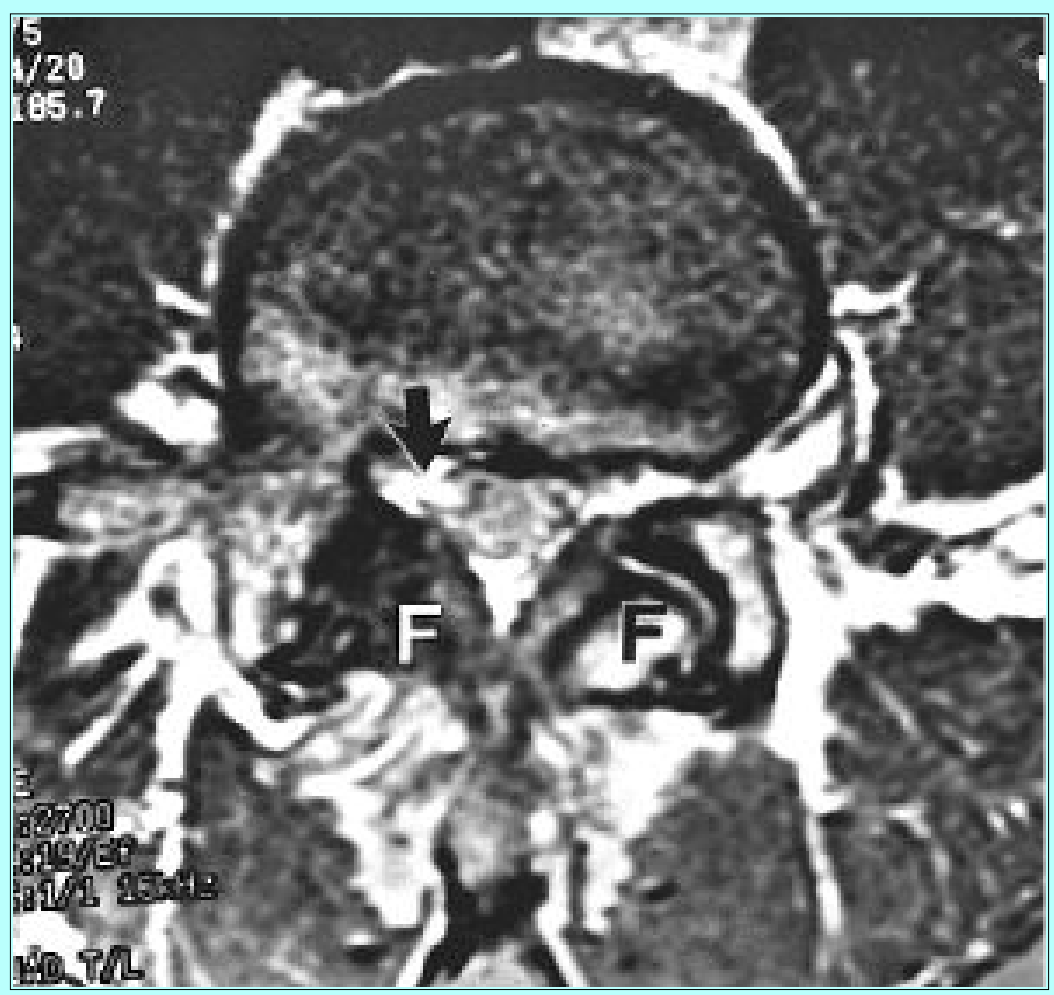

Fig. 2. Magnetic resonance image demonstrating bilateral facet hypertrophy $(\mathrm{F})$ and soft disc herniation (arrow).

Same-day, microsurgical, arthroscopic, lateral approach, laser-assisted fluoroscopic discectomy[14] was performed via a unilateral monoportal method by using a $\mathrm{C}$-arm image intensifier, a working discoscope, and a neodymium:yttrium-aluminum-garnet laser. After insertion of a working sheath with a $6.5-\mathrm{mm}$ diameter, a corer allowed removal of some osteophytic ridging. Fluoroscopic monitoring of instrument location was alternated with direct fiberoptic visualization of the forceps removing disc material and the laser fiber producing hemostasis. The amount of nucleus pulposus removed varied from 2 to $5 \mathrm{~g}$.

\section{RESULTS}

No complication of increased neurological deficit, wound infection, discitis, cerebrospinal fluid fistula, or hemorrhage occurred with either minimally invasive method. Three patients (two of whom underwent minilaminotomies and one who underwent same-day, microsurgical, arthroscopic, lateral approach, laser-assisted, fluoroscopic discectomy) who were not sufficiently improved after 2 months were reevaluated by using gadolinium-enhanced MR imaging; the neuroradiological imaging revealed only postoperative changes at the correct level. Prolonged treatment with nonsteroidal antiinflammatory drugs was necessary. After at least 1 year of follow-up study, the 20 patients who underwent microsurgical or arthroscopic procedures limited to removing the ruptured disc have not required more extensive decompression.

\section{DISCUSSION}

Although the medical literature from the 19 th century[5,9,10] contains articles on lumbar stenosis and appropriate surgical intervention was available as early as 1900,[11] full comprehension of narrow canal syndrome was not achieved until the middle of the 20th century.[15] The source of a herniated nucleus pulposus was identified as the intervertebral disc in 1934; [8] however, spinal stenosis was not appreciated as a separate cause of sciatica and neurogenic claudication until 1953 when Malis, et al.,[7] 
introduced full-column myelography imaging of the spinal canal in the presence of disc disease at multiple levels. Decompressive laminectomy for relief of cauda equina compression due to hypertrophic laminae, enlarged facet joints, and thickened ligamenta flava was already widely practiced when Farfan[4] emphasized osteoarthritic changes in the three-joint complex consisting of the two posterior facets and the anterior disc at each level of the spine.

Additional articles by Epstein and coworkers[2,3] added to the understanding of segmental spondylosis and lateral recess syndrome; posterior osteophytes and subligamentous herniation of even small amounts of nucleus pulposus may contribute to nerve root compression within a small canal and produce a radicular pattern of pain. Neurogenic claudication associated with narrow canal syndrome can mimic vascular claudication due to aortoiliac occlusive disease. Clinical features include intense dysesthesias and numbness in the lower limbs when walking or standing in a position that accentuates lumbar lordosis. Symptoms may disappear when sitting or assuming the recumbent position because changing posture or bending forward allows the canal to assume a more generous dimension that relieves pressure on neural elements. Computerized tomography scanning facilitates imaging of the exact shape and dimensions of the bony spinal canal, whereas MR imaging provides additional evidence of multiple bulging discs, hypertrophic ligamenta flava, large osteophytic ridges, and narrowness of the dural sac.[13]

\section{CONCLUSIONS}

Whereas an array of neuroradiological and other diagnostic studies are available for lumbar stenosis, the decision to intervene surgically should encompass evaluation of the procedure most suitable for the patient with sudden onset of single soft disc herniation. Minimally invasive surgery has proven to be an acceptable approach to herniated nucleus pulposus in patients with a history and neurological examination documenting a single nerve root syndrome even when CT or MR imaging reveals a narrow canal.

\section{References}

1. Burton CV: Causes of failure of surgery on the lumbar spine: ten-year follow-up. Mt Sinai J Med 58:183-187, 1991

2. Epstein JA, Epstein BS, Lavine L: Nerve root compression associated with narrowing of the lumbar spinal canal. J Neurol Neurosurg Psychiatry 25:165-176, 1962

3. Epstein JA, Epstein BS, Lavine LS, et al: Lumbar nerve root compression at the intervertebral foramina caused by arthritis of the posterior facets. J Neurosurg 39:362-369, 1973

4. Farfan HF: Mechanical Disorders of the Low Back. Philadelphia: Lee \& Febiger, 1973

5. Jaccoud S: Les Paraplegies et l'Ataxie du Mouvement. Paris: Adrien Delahaye, 1864

6. Malis LI: Lumbar stenosis. Mt Sinai J Med 58:121-124, 1991

7. Malis LI, Newman C, Wolf BS: Full column technique of lumbar myelography. Radiology 60:18-28, 1953

8. Mixter WJ, Barr JS: Rupture of the intervertebral disc with involvement of the spinal canal. N Engl J 
Med 211:210-215, 1934

9. Parrot MJ: Sur la malformation achondroplastique et le Dieu Phtah. Bull Soc Anthropol 1:296, 1878 10. Portal A: Cours d'Anatomie Medicale ou Elemens de l'Anatomie de l'Homme. Paris: Baudouin, 1803, Vol 1, p 299

11. Sachs B, Fraenkel J: Progressive ankylotic ridging of the spine (spondylose rhizomelique). J Nerv Ment Dis 27:1-15, 1900

12. Savitz MH: Minilaminotomy as an alternative to laminectomy or microdiskectomy: ten years' experience. Mt Sinai J Med 58:165-167, 1991

13. Savitz MH: Preoperative and postoperative neuroradiologic evaluation of lumbar disk herniation. Mt Sinai J Med 58:129-132, 1991

14. Savitz MH: Same-day microsurgical arthroscopic lateral-approach laser-assisted (SMALL) fluoroscopic discectomy. J Neurosurg 80:1039-1045, 1994

15. Verbiest H: Sur Certaines Formes Rares de Compression de la Queue de Cheval. I. Les stenoses osseuses du canal vertebral. Paris: Hommage, Clovis Vincent, 1949

Manuscript received June 16, 1997.

Accepted in final form July 15, 1997.

Address reprint requests to: Martin H. Savitz, M.D., 55 Old Turnpike Road \#101, Nanuet, New York 10954. email: drbcasey@aol.com. 